\title{
Coal and Coke for Blast Furnaces
}

\author{
Heribert BERTLING \\ Managing Director, RAG Aktiengesellschaft, Wolfskuhle 40, 45529 Hattingen, Germany.
}

(Received on November 13, 1998; accepted in final form on March 25, 1999)

\begin{abstract}
The main charge material for the steel production is liquid hot metal. It is mainly produced in blast furnaces. The blast furnace operates according to the counter-current principle. The process makes the blast furnace reliant on lumpy materials to maintain a gas-permeable stock column. The most important reducing agent is therefore the lumpy coke. Auxiliary reducing agents, such as coal or oil, are injected via the tuyeres. The tasks of coke and coal for the hot metal production and the requirements of the blast furnace on coal- and coke-quality are described.

The consumption of coal and coke in the blast furnace is met on the one hand by the market or on the other hand by the own production. It depends on the conditions of the market and the availability of production facilities. World-wide the production of hot metal and crude steel via the blast furnace/converter route is regarded as the dominant process line also in future. Consequently, after their successes in the past, the ironmaking and steelmaking industry have joined their efforts with the cokemaking industry to exploit still more development potentials for hot metal production.
\end{abstract}

KEY WORDS: blast furnace process; tasks of reducing agents; quality requirements for coal and coke; development of coking technology.

\section{Introduction}

Steel will remain the basis for economic development in the world. Steel consumption will tend to follow the development in gross national product in the world.

In 1997 approximately 800 mill. $t$ of crude steel were produced worldwide, for which corresponding iron bearing materials had to be available (Fig. 1). The main charge material was liquid hot metal which accounted for nearly 545 mill. $t$ in 1997 . The hot metal to crude steel ratio was approximately $700 \mathrm{~kg} / \mathrm{t}$ crude steel in 1996. It is an interesting fact that the use of hot metal remained more or less the same since the year 1930, the production at that time being approx. 100 mill.t crude steel and approx. 75 mill. t hot metal.

The other charge materials reported for the year 1997 were 350 mill.t steel scrap and 36 mill.t solid direct reduced sponge iron (Direct Reduced Iron and Hot Briquetted Iron). Taking into consideration that $1.15 \mathrm{t}$ iron bearing materials are used to produce one ton of crude steel hot metal presents $60 \%$. Today this quantity of hot metal is nearly exclusively produced in blast furnaces based on coke.

As steel with its advantages in manufacturing, processing and quality properties, is and will remain dominant it is anticipated that in future worldwide steel production will have an increase in demand corresponding to the growth rate of population. An average minimum of $1.5 \%$ per year is forecast. ${ }^{1)}$

\section{The Blast Furnace Process}

Figure 2 shows the principles of the blast furnace process. The blast furnace operates according to the counter-current principle. The solid lumpy feed materials, such as iron ores, coke and low amount fluxes are charged at the furnace top. The oxygen content of the hot blast blown in through the tuyeres in the lower part of the furnace reacts with the carbon in the reducing agents, such as coke, coal and oil, to produce a reducing gas, which ascends in the stack and extracts the oxygen from the ores. Temperatures of up to $2200^{\circ} \mathrm{C}$ develop in the front of the tuyeres.

Melting separates the formed iron and the remaining constituents of the ores to hot metal and slag.

Hot metal and slag are tapped via tapholes in the blast

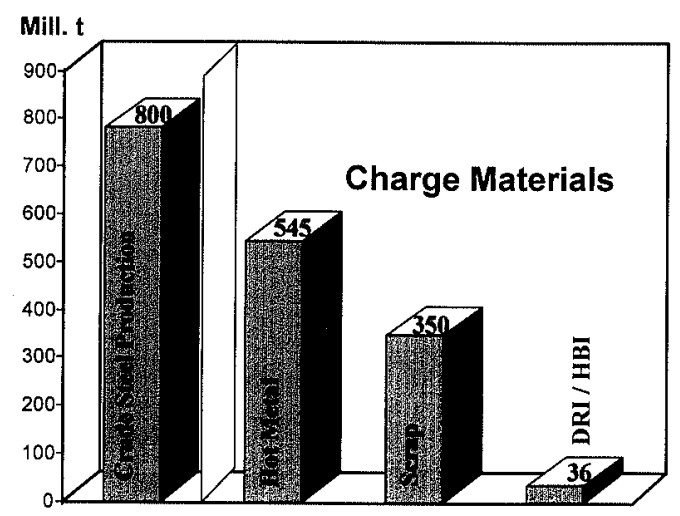

Fig. 1. Charge materials for crude steel production. Source: IISI Statistics 1997. 
furnace hearth. Surplus gas is drawn off at the furnace top, cleaned, and used in the iron and steel works for heating purposes.

The process principle makes the blast furnace reliant on lumpy materials to maintain a gas-permeable stock column. For this reason fine-grained iron ores are agglomerated, that means sintered or pelletized, before being charged into the blast furnace. Auxiliary reducing agents, such as coal, oil, gas or old plastics, are injected via the tuyeres in order to save coke.

For competitiveness in the international market integrated iron and steel works with high output rates today operate only a few furnaces, in many cases only one to three, being designed for a production of up to 12000 tons hot metal per day.

The high technical "status quo" of ironmaking in the blast furnace has been achieved by constant further development of the plant and process engineering. The "stormiest" development phase occurred during the past three decades, coupled with developments in plant engineering, the quality and supply of raw materials as well as comprehensive process monitoring and control.

In the last 25 years the average productivity of all

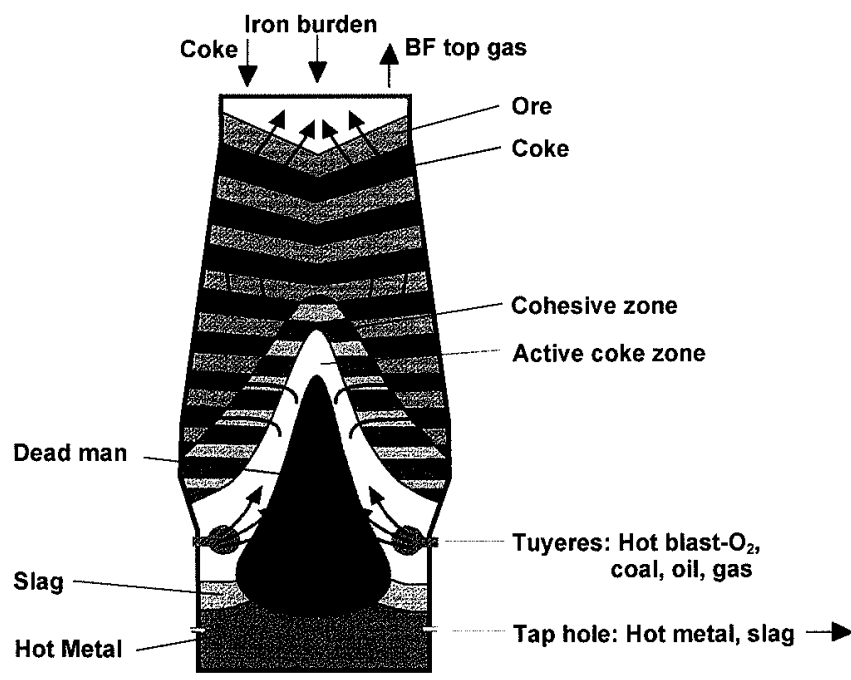

Fig. 2. Simplified scheme of the blast furnace process.
German blast furnaces for example increased by $60 \%$. A productivity increase of a blast furnace is coupled with an increase of the gas throughput and a reduction of the specific gas volume. ${ }^{2)}$ A reduction of the specific gas volume can also be obtained by reducing the specific reducing agent consumption. The trend for German blast furnaces is shown in Fig. 3. The total reductant rate was decreased from $800 \mathrm{~kg} / \mathrm{t} \mathrm{HM}$ in the 1960 s to below $470 \mathrm{~kg} / \mathrm{t} \mathrm{HM}$ in 1997.

From Fig. 3 it could also be seen that the closer the reducing agents consumption gets to the process technological minimum, the flatter the curve becomes. However, additional productivity reserves could be utilized by changing the reducing agent structure in conjunction with the use of higher amounts of oxygen as well as improvements in iron burden quality. There still remains potential for further process improvements. ${ }^{3)}$

\section{Reducing Agents}

The main reducing agents for hot metal production in a blast furnace are coke, coal, oil or gas. In the past coke was replaced by oil and during the last decades more and more by coal.

The use of coal, oil or gas depends on the economical result of BF-operation.

The technology of pulverized coal injection (PCI) has reached a high standard. All high productivity $\mathrm{BF}$ are equipped with PCI-facilities.

It has to be noted that the blast furnace process produces its reducing gas inside the furnace itself. As the coke is the most expensive charge material of the blast furnace the operators replace coke partly by the injection of carbon and hydrocarbon carriers via the tuyeres using high blast temperatures and oxygen to guarantee a suitable flame temperature and a fully gasification rate of the injectants to reducing gas.

The injection of coal leads to an optimization of the process chain. The replacement ratio of coke to coal is in the range of 0.9 to 1.0 ; so it saves costs, as the injection of coal requires only $20 \%$ of the specific investment costs for a coking plant and only $30 \%$ of the processing

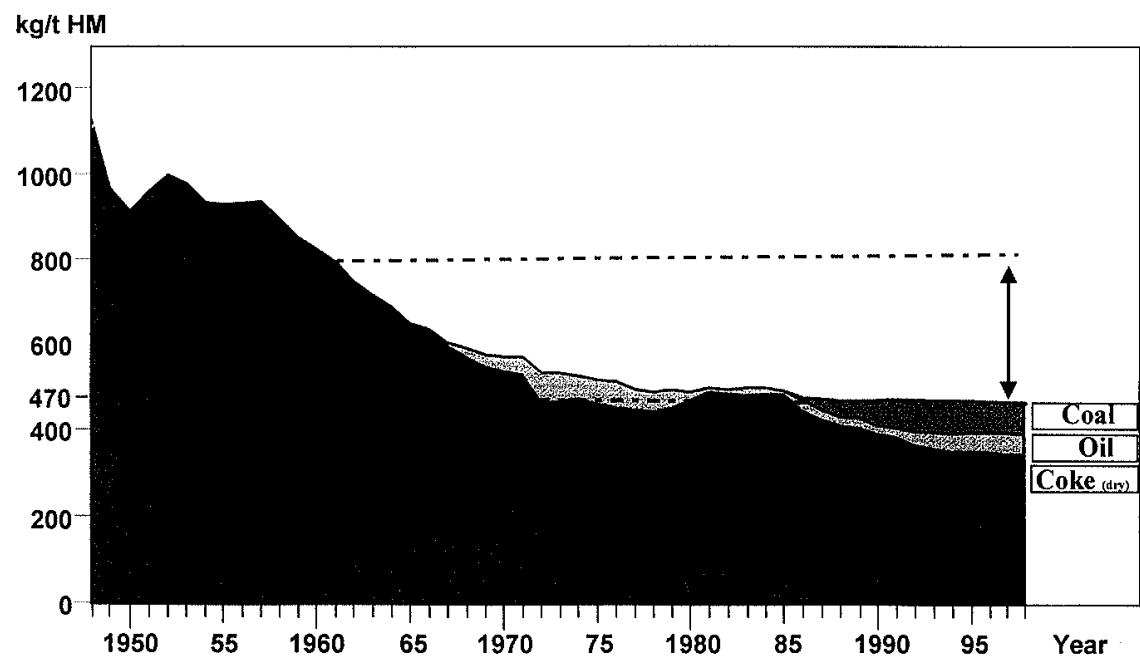

Fig. 3. Average consumption of reducing agents at the blast furnaces in Germany. Source: VDEh Blast Furnace Committee. 
costs. For the amount of coal injected the BF slag partly takes over the purpose of the coking plant by-product processing facility.

At individual blast furnaces coke rates of below $300 \mathrm{~kg} / \mathrm{t} \mathrm{HM}$ have been achieved by the injection of coal or oil.

Nevertheless coke will remain the most important reductant in the future.

Coke plays a triple role in the blast furnace, namely a physical, thermal and chemical role, of which physical and chemical are most important.

Physical Role: As iron ores change their chemical and physical properties from top to the hearth of the furnace according to reduction, softening and melting the coke remains the only solid material below the smelting zone of the iron bearing materials. On the one hand, it forms a strong grid which supports part of the weight of the overlying burden and on the other hand, it constitutes a highly permeable "trickling column" which allows an adequate drainage of the molten materials slag and hot metal and a good distribution of the gases ascending from the raceway at the tuyeres.

A very important role is credited to the coke in the so-called "cohesive zone", that means the region where the softening and melting iron-bearing materials are believed to form impermeable layers, separated by "coke windows". This is why a blast furnace operation without coke is not possible for physical reasons.

In the blast furnace hearth the coke forms a cone, the so-called "dead man", which should be permeable for hot metal, slag and the furnace gas.

Thermal Role: The carbon of the coke and of the injectants supply the major part of the heat required for the process, which accounts for $80 \% .20 \%$ are supplied by the hot blast.

Chemical Role: The coke supplies carbon for the production of reducing gas, the regeneration of $\mathrm{CO}_{2}$ by the solution loss reaction in the high temperature zone, as reductant for the direct reduction of Iron oxide, for the reduction of alloying elements like silicon and manganese and last but not least, the carbonization of hot metal, which is important to decrease the melting temperature of iron.

\section{Coal- and Coke-quality Requirements}

Quality requirements for coal and coke can be derived from the tasks in the blast furnace in conjunction with the mode of blast furnace operation.

The requirements on coal quality are especially referred to the chemical composition of the minerals. The main problems are related to tramp elements.

Especially alkalis and zinc have highly detrimental effects because they disturb the regularity of the furnace operation and entail higher reducing agents consumption, a loss in furnace productivity and in consistency of the hot metal quality.

Sulphur can be eliminated from the hot metal down to required values partly by the blast furnace slag and by a separate desulphurization prior to the steel shop, but its removal can become extremely costly.
Table 1. Requirements on chemical composition of coke in Germany.

\begin{tabular}{ll}
\hline Ash & $<9.0 \% \mathrm{mf}$ \\
Volatile matters & $<0.75 \% \mathrm{mf}$ \\
Sulphur & $<0.70 \% \mathrm{mf}$ \\
Alkalis $\left(\mathrm{Na}_{2} \mathrm{O}+\mathrm{K}_{2} \mathrm{O}\right)$ & $<0.20 \% \mathrm{mf}$ \\
Chlorine & $<0.05 \% \mathrm{mf}$ \\
Phosphorus & $<0.03 \% \mathrm{mf}$ \\
Zinc & $<0.003 \% \mathrm{mf}$ \\
\hline
\end{tabular}

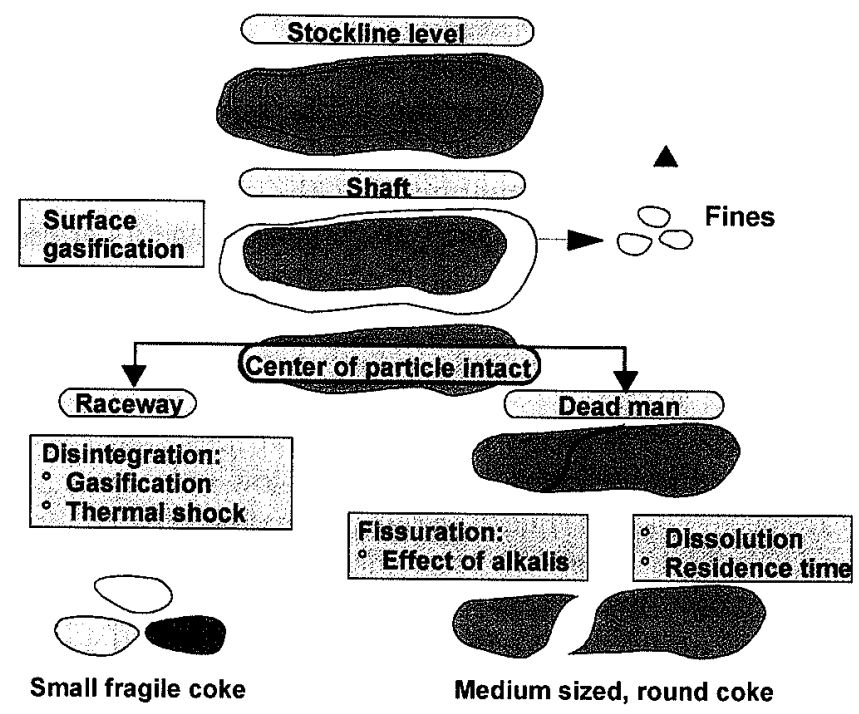

Fig. 4. Schematic representation of the coke degradation in a blast furnace.

It has to be noted that it is difficult to move sulphur and alkalis from the blast furnace simultaneously, which both should be discharged via the slag. Sulphur could only be compound in a basic slag and removed from hot metal whilst alkalis could only be compound in an acid slag. With the today's alkali input into German blast furnaces of up to $3.5 \mathrm{~kg} / \mathrm{t} \mathrm{HM}$ the hot metal needs to be desulphurized outside the blast furnace before it is charged into the basic oxygen converter to the required low values.

Other properties of coal are not so significant.

Coke quality requirements on chemical composition for the operation of big blast furnaces with low coke rates, high productivity and the production of hot metal of uniform chemical composition and temperature are listed in Table 1.

The ash content of the coke in itself is rarely a major problem for furnace operation, but nevertheless high coke ash can mean higher slag volumes and consequently higher energy consumption and lower furnace productivity. The main problems with coke ash are related to tramp elements. Here are the same effects caused by the minerals of injected coals.

Coke moisture and chlorine can be a problem for an efficient furnace operation, because they increase the dew point of the top gas and either impose a thermally inefficient operation with higher top gas temperatures or, if the top temperatures drop too low, they cause condensation and corrosion in the gas lines and dedusting equipment. ${ }^{4)}$

Figure 4 shows a schematic representation of the coke 
Table 2. Requirements on physical properties of coke in Germany.

\begin{tabular}{lc} 
CSR $(\%<10 \mathrm{~mm})$ & $>65 \%$ \\
CRI & $\operatorname{max.} 23 \%$ \\
$\mathrm{I}_{40}>40 \mathrm{~mm}$ & $>55 \%$ \\
$\mathrm{I}_{10}<10 \mathrm{~mm}$ & $<15 \%$ \\
Grain size: & \\
$>80 \mathrm{~mm}$ & $\operatorname{max.} 10 \%$ \\
$<40 \mathrm{~mm}$ & $\operatorname{max.} 18 \%$ \\
$\quad<20 \mathrm{~mm}$ & $\operatorname{max.} 3 \%$ \\
\hline At delivery before drumming. &
\end{tabular}

degradation in a blast furnace. ${ }^{5}$ The coke is attacked by mechanical load, by alkalis and by gasification. The lumpy bell coke for guaranteeing the counter current principle of the process shall not much change its grain size and grain form up to the temperature range of $1500^{\circ} \mathrm{C}$. Therefore the coke must be stabilized, fissure free and must have a cold strength $\mathrm{I}_{40}$ (IRSID-test) of $55 \%$ plus $40 \mathrm{~mm}$.

Coke physical properties are of great importance for the blast furnace operation with very low coke rates as they occur when the injection rates of auxiliary reductants are very high (Table 2 ). Here the longer residence time of the coke in the very high temperatures region, the chemical attack by liquids and gas, the gasification by the Boudouard reaction $\left(\mathrm{C}_{\mathrm{coke}}+\mathrm{CO}_{2} \rightarrow 2 \mathrm{CO}\right)$ to regenerate reducing gas and supplementary abrasion by for example injected coal particles can enhance the coke degradation in the furnace bosh and tuyere level.

In the hearth of the blast furnace the coke cone ("dead man") must confer a sufficient permeability, so that slag and hot metal can easily flow downwards and it must guarantee a proper drainage of the hearth. Tapped volume of hot metal and slag and tapping time are closely related to coke size. Too small coke entails the formation of an impermeable inert central core in the blast furnace, which deviates gas and liquid flow towards the walls of bosh and hearth. This can lead to disastrously rough furnace operation, wear of the refractory lining and breakouts!

High temperature properties of coke are generally expressed in terms of the CSR value (Coke Strength after Reaction with $\mathrm{CO}_{2}$ ) and the CRI value (Coke Reactivity Index). Both values are measured in one test procedure under gasification of a coke sample with $\mathrm{CO}_{2}$ at $1100^{\circ} \mathrm{C}$. The CRI value is measured by the loss of coke weight after reaction and the CSR-value after mechanical stress is expressed by the grain size portion of $+10 \mathrm{~mm}$.

Because of the known fact that blast furnaces are operated stable also with cokes being poor in CSR values, it is questionable whether there may be other coke quality criteria not known today which describe the behavior of coke in the blast furnace much more precisely. Appropriate test procedures need to be developed.

However, experience shows that the CSR-value is of great importance for very large blast furnaces and furnace operation with extreme low coke rates at high productivity.

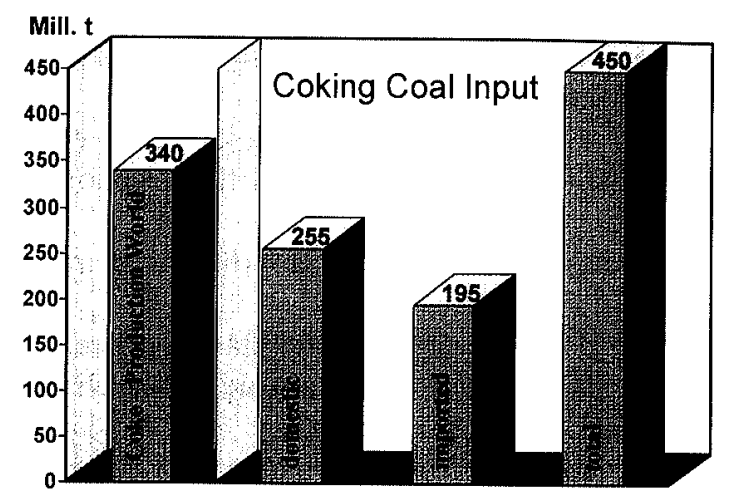

Fig. 5. Demand on coking coal worldwide.

\section{Performance with the Demands of the Blast Furnace}

The consumption of coal and coke in the BF is met by the market or the own production.

Coals for injection are available on the world market without any problems; because there are no special quality requirements for this purpose.

Input coals for coke production have attained even greater importance. Along with more exacting demands raised by blast furnaces for coke quality the choice of suitable coking coals has become more difficult. High strength in conjunction with a sufficient reactivity of coke today call for a more differentiated evaluation of coal to be charged.

The crucial factor for the quality of coke regarding raw materials are the baking capability of input coal permitting the production of a solid and dense coke in coarse lumps.

Moreover, other factors being important are the ash content and the composition of ash which in turn influence the quality of coke for blast furnaces.

High-grade coking coals are available above all in Australia, Canada, the United States of America and Poland.

For a coke production of about 340 million tons on 250 coking plants world wide the consumption of coking coals amounts approximately 450 million tons. About $60 \%$ are used from domestic coal mines. Nearly 200 million tons are imported coals from the international market $^{6)}$ (Fig. 5).

The largest importing country is Japan with an amount of nearly 75 million tons of coking coal in 1997.

In the last years, the demand for coking coals has risen on international markets. Consumption at present obviously stabilizes at a high level. A quantity of approx. 225 million tons of coking coal is offered on world markets in the year 1997. There is a demand for approx. 195 million tons. It results in a surplus supply of approx. 30 million tons. These quantities are mainly launched on the market as pulverized injection coal or power station coal.

On a worldwide level, however, there are some acute supply bottlenecks in some quality fields.

A growth in coking coal consumption in the future had been expected exclusively in the Asian countries, e.g. in China, Korea and Taiwan, while most of the other regions are expected to suffer from cutbacks in capacities 
and a further decline in the demand for reducing agents in blast furnaces which will lead to a lower demand for coking coal. In Europe and in the former Comecon countries, the demand, but also the availability of coking coals will tend to fall.

On the whole in the last years a shortage in the availability of coking coal, mainly by the South Asian region, was supposed to occur worldwide in the medium term.

The principal supplier countries of coking coal are the USA and Australia. American mines rather dispose of high-volatile components, while Australian mines to a greater extent have low-volatile components available. If supplies are disturbed, e.g. due to industrial action, it will be difficult to find major quantities of complementary blend components needed for coals available in that case in other countries.

Hence it is quite understandable that consumers intensify their search for participation in coking coal mining pits all over the world in their strife for assured supplies.

After the financial crisis in most of the Asian countries the future market has been changed. The described bottlenecks are no longer as acute as before.

The future market for coking coal depends on various elements:

Because of the general downturn in international markets, steel products from emerging countries are finding little market in Asia and try to find their way into Europe and North America. European steel mills are forecasting lower productions for the next year.

Because of environmental constraints new coking plants are hard to be built and financed. Because of low oil and gas prices pulverized coal injection plants are less feasible. More steel works show a tendency to producing steel by electrical arc furnaces.

On the consumption side of the equation, the Asian countries have declared, that they will use much less coking coal in 1999 than in the previous years. A reduced consumption of 10-15\% just in Asia will result in 20-30 Million tons of coking coal that are uncommitted for. Only countries with a strong domestic market like Brazil of with a shrinking indigenous production like Germany and France will offset some demand of the Asian countries.

The consumers of coking coals are nearly all directly dependant on the steel industry. A down turn in this industry will hit the coal industry hard. The export of coking coal will shrink from the US and Poland, whereas exports of Australian and Canadian coking coal will go back mildly because of the softer currencies towards the US-Dollar.

It can be concluded:

- The demand for coking coal will shrink.

- There will be greater need for low and medium volatile coal instead of high volatile.

- Mines will close in USA and Poland and new global players will emerge taking over mines in distress.

- Prices for coking coal will go down in USD-terms but might be set off by higher prices in Australian and Canadian Dollar terms.
- Delivered prices and consequently origins of coal will be determined by the level of ocean transportation cost. Taking a glance at the market for merchant coke, it can bee concluded, that there is just a minor volume as compared with the total coke consumption world wide.

The principal bidders for the international coke trading are Japan, China and Poland.

Japanese plants work at full capacity and supply coke merely to those clients having high demands for quality.

China exports a qualitatively very different coke which consumers in most cases utilize as admixing component only.

In Poland, there are approx. 2 million tons available for exports. But there it is prudent to take caution because coking coal price trends run opposite to those observed on the world market.

The coke market is particularly tight where the use of Chinese coke is shunned from for quality considerations.

To get a prospective view on the availability of coke, one should look to the state of the coking capacities in the world. Considering an average technical service life expectancy of coke plants in a range of 20 to 25 years, a major portion of the plants being on stream is overaged.

Another point to be considered in an evaluation is the technical status and the layout of the plants. The majority of plants in West Europe as well as of the plants in Japan, Korea and Taiwan has reached a status that will ensure a long-term operation. In the other regions of the world, a high deficit in maintenance is evident. Besides, these coke plants are not equipped with sufficiently effective technologies for environmental protection.

More stringent rules imposed in various countries also lead to capacity constraints because the appropriate environmental protection measures cannot be materialized at once. Even a substitution of old coke plants will take at least 3 to 5 years, because of the high costs of capital investment and the lengthy procedures required to obtain approvals.

Based on a critical assessment of records and figures available now, a global shortage in coke making capacities will have to be expected to occur after the year 2000. Latest from that point of time on, new coke making capacities will have to have been constructed, even if the coke rate in blast-furnaces is optimized and if the reducing agents coal and oil have further grown in application.

It will be necessary right now to make every effort to diminish the anticipated bottlenecks in supplies of coke. There are varoius possible technical solutions available.

Coke oven batteries are constantly subjected to high mechanical, thermal and, to some degree, even chemical strains and stresses which initially entail fine cracks and surface damage, but which may lead to a destruction of entire wall sections later-on. All the damage of this kind or similar by nature, too, which occur more and more frequently as the operation time of coke oven batteries takes on and on, will cause substantial costs to be spent on capacity preservation.

To preserve the production in existing coke plants, the following viable solutions are available:

- repair by guniting, ceramic welding and new 


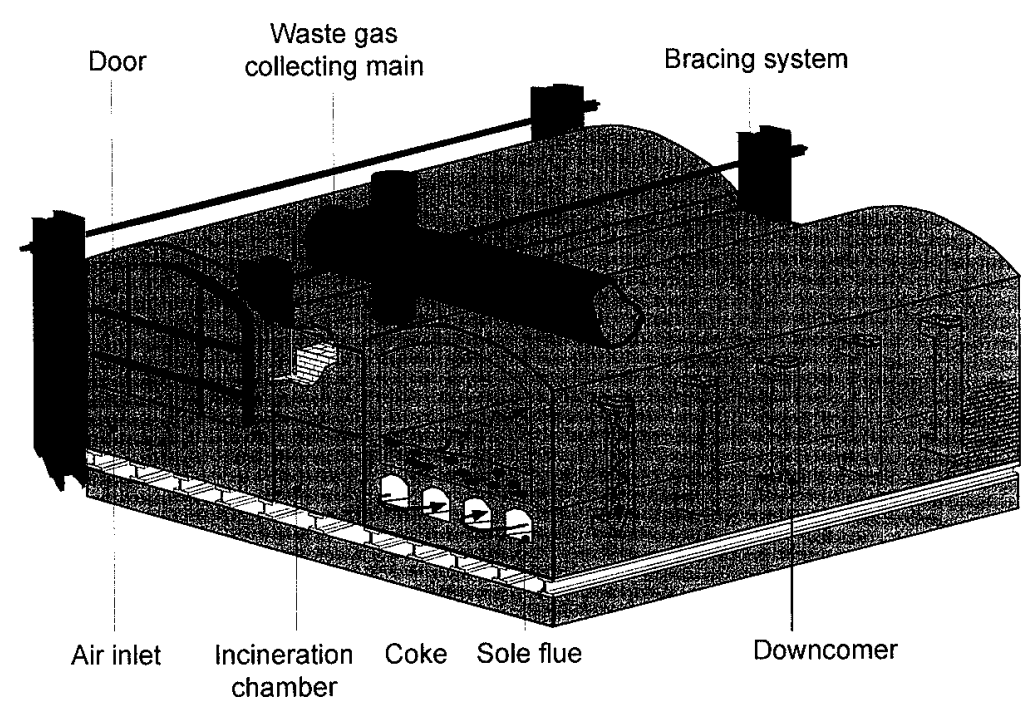

Fig. 6. Non-recovery process.

bricking-up of coke oven walls

- partial renewal or pad-up renewal of coke oven batteries

- completely new coke plants as substitutes

Guniting, ceramic welding and partial bricking-up can bridge only short time gaps. A sustained assurance of production cannot be achieved by these measures. Of the possibilities contemplated here, only a partial pad-up or a complete pad-up renewal will bring a long-term success. By implementation of this procedure, it will not be possible to achieve any essential technical improvements and not at all any streamlining effects. No restrictions to the technical service life are reachable by complete substitution or new construction of coke plants.

The potential for a growth in production on existing coke plants is the use of predried and preheated coal which also will lead to an improvement in productivity, but also in coke quality and energy consumption.

Though an integration of a thermal coal pre-treatment system retrofitted into existing plants is feasible, it calls for substantial expenditure. Intensive efforts geared to coal pre-drying and preheating were taken in the past years, particularly in Japan. Nippon Steel has already been applying a process for coal pre-drying since the $80 \mathrm{~s}$.

The disappearance of overaged coke making capacities is partly compensated by modern blast furnace technologies employing high rates of pulverized coal and oil injection. The technological progress made in the field of hot metal production will also call for higher requirements on coke quality.

Stringent environmental protection standards, particularly those imposes in Western industrialised countries, as well as a rational exploitation of energy in coke making process technology should be integrated and considered in future deliberations and analyses.

Currently the coke making industry worldwide pursues three initiatives for further advances in existing coke making systems:

- non-recovery process in the USA

- combined process-Scope 21 in Japan and
- single coking reactor in Europe.

The features of these three process developments are briefly outlined in the following.

The non-recovery process differs from the old beehive oven of the 19th century only in the exploitation of waste heat for steam and electric power generation (Fig. 6).

The benefits of this process lie in the simple design and operation as well as in the omission of the byproducts recovery.

The drawback of this system in particular lie in the waste heat exploitation: large superheated waste gas streams must be fed over long distances to a central boiler house. Standing at the end is the necessary flue gas treatment with all its process problems and costs.

Another constraint is suffered by the process with regard to the feedstock basis of charging coals that can be used. Only low-volatile and well-coking coal can be charged. Further disadvantages such as a less coke yield and, conditioned by the grain size, a less blast furnace coke yield. Inspite of these disadvantages in the USA the first high capacity plant has been taken into operation at Inland Steel, Chicago. This technolgy is only demanded for ecological reasons. ${ }^{7)}$

The starting point for the development approach in the Japanese coke making industry are some disadvantages of the conventional coke making system such as high capital investment costs, a narrow coking coal feedstock basis, and the compulsory necessity to come to a sensible relief for the environment (Fig. 7).

In the current development, a multiple-stage coke process is favoured. The development is built upon conventional process steps. But their complexity will still take several years of technical improvement. The status of work today is confined to scientific investigations at various universities in Japan.

The striking features of the Single Coking Reactor System in Germany are the disintegration of coke ovens from the battery compound and the free choice of dimensions. The main design feature of the reactor is the single chamber system contrasting with the multichamber coke making technolgy applied nowadays. Each 


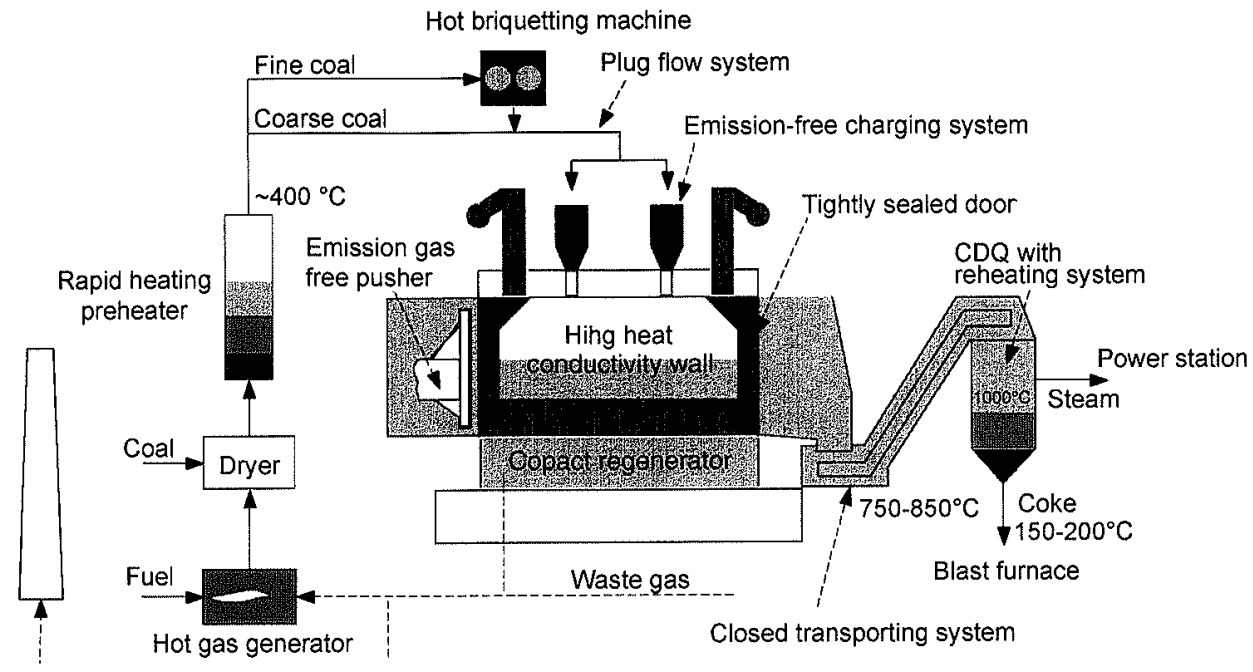

Fig. 7. Scope $21-$ Combined process.

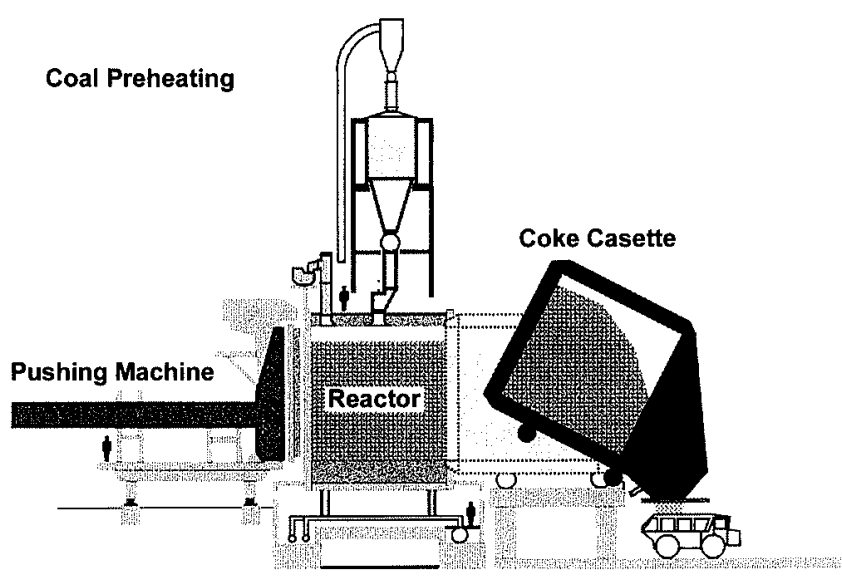

Fig. 8. Single chamber system (SCS).

single reactor represents an entirely autarkic coke making unit. The mechanica of stability applied thus far, restraining the brickwork through roof load and buckstay, is abandoned to the benefit of statically independent construction modules. Oven chamber, heating flues and additional insulation layers are restrained between rigid walls. Coking pressures that occur in a range of up to 3 bar will be deflected into the supporting structure, thus causing no damage at all. ${ }^{8}$

In Germany a demonstration plant has been operated on the Prosper coke plant since 1993 which includes a coal preheating unit and a programmed heating (Fig. 8)

The test results give good cause to expect operational advantages, primarily in consumption of energy. Coke qualities obtained could be improved over conventional coke. It gives the chance to use a major portion of non-coking, low-cost coals. This development represents a progressive alternative, providing for broader liberty in operation and choice of raw materials.

\section{Outlook}

Experience gained from blast furnace operation and the development of the blast furnace process show that excellent operation results require excellent charge materials, that means excellent chemical and physical properties of iron bearing materials, coke and auxiliary reductants. As coke has the role of guaranteeing the permeability in all areas of the blast furnace further optimization of furnace operation are accompanied with further improvements in coke quality. Therefore it is questionable whether the existing characterization of coke quality is sufficient to describe the behavior of coke in the blast furnace satisfactorily. It may be necessary to further determine the stress behavior of coke in the softening and liquid areas of the blast furnace to develop new test procedures for the characterization of coke.

This should result in better coke qualities which enable blast furnace operators to further reduce coke rates through increased rates of injectants and to increase productivity and therefore the output rates of the blast furnaces.

This will lead to a decrease in operating costs of the blast furnace and capital costs by the avoidance of corresponding coking capacities. The result is a better competitiveness of integrated iron and steel works using the blast furnace/oxygen converter route.

Coke plant operators are confronted with steadily increasing requirements from the blast furnace operators on coke quality, especially on the CSR value. This could be achieved with the single chamber system using extended coal base, which may result in higher wall pressures.

In fact, it is a decision of the individual steel producers whether they believe in the availability of coke on the world market or whether they modernize an existing or build a new coking plant. Building a coking plant has the disadvantage of high investment costs but the advantages that on the one hand the coke is consumed directly where it is produced (avoiding long transportation distances) and that on the other hand a coking plant generally fits excellent into an energy network of an integrated iron and steel work.

World-wide the production of hot metal and crude steel via the blast furnace/converter route is regarded as the dominant process line also in future. Consequently, after their successes in the past, the ironmaking and steelmaking industry have joined their efforts with the 
cokemaking industry to exploit still more development potentials for hot metal production.

\section{REFERENCES}

1) IISI Forecast, (1997).

2) W. Hartig, K. Langner, H. B. Lüngen and K. P. Stricker: $M P I$ Int., 4 (1996), 42.
3) H. Hille, W. Lanzer, H. B. Lüngen, and R. Sieger: Staht Eisen, 117 (1997), No. 3, 93

4) A. Poos: Cokemaking International, 4 (1992), No. $2,29$.

5) ECSC Research Projects $7220-E B / 202$ and $7220-E B / 338$, (1994).

6) H. Bertling and U. Strobel: Cokemaking International, 8 (1996), No.1, 20

7) N. L. Samways: Iron Steel Eng., 12 (1997), 17.

8) H. Baer, H. Bertling, and W. Rohde: ICST / Ironmaking Conf. Proc., (1998), 789 